\title{
"MEWARISKAN KEBERPIHAKAN LEWAT MUSIK" Suatu Interpretasi Teologis yang Berpihak Kepada Penyandang Disabilitas terhadap Lagu "Fly"،
}

\section{Kritsno Saptenno}

\author{
Mahasiswa Pascasarjana Teologi Universitas Kristen Duta Wacana \\ email: kritsnosaptenno15@gmail.com
}

\begin{abstract}
Church music in Christianity is one of devices used to internalize value to the people. But, the value inherited in music tends towards human relations with God (worship), so that it does not take sides with the social issues, such as the existence of persons with disabilities. This is different with product of popular culture, like pop music that actively shows the alignments with persons with disabilities, for example the song "Fly" by Avril Lavigne. The aims of this paper is showing the alignments of popular culture products to person with disabilities, so religious communities such a church can learn to become community that is pro-people with disabilities.
\end{abstract}

Keywords: Church music, popular culture, disability, Fly song

\begin{abstract}
Abstrak
Musik gereja dalam agama Kristen adalah salah satu perangkat yang digunakan untuk menginternalisasikan nilai-nilai kepada umat. Akan tetapi, nilai yang diwariskan dalam musik cenderung diarahkan kepada relasi manusia dengan Tuhan (penyembahan), sehingga keberpihakan kepada isu sosial seperti keberadaan para penyandang disabilitas tidak mendapat tempat. Hal ini berbeda produk budaya populer, seperti musik pop yang giat menunjukan keberpihakannya kepada para penyandang disabilitas, semisal lagu Fly karya Avril Lavine. Makalah bertujuan untuk memperlihatkan keberpihakan musik pop kepada para penyandang disabilitas, sehingga komunitas religius seperti gereja dapat belajar untuk menjadi komunitas yang berpihak kepada penyandang disabilitas.
\end{abstract}

Kata kunci: Musik gereja, budaya populer, disabilitas, lagu Fly 


\section{PENDAHULUAN}

Maraknya praktik-praktik kesembuhan ilahi (Divine Healing) muncul mengikuti kelahiran gerakan Pentakostalisme di Amerika Serikat pada periode 1990an. ${ }^{1}$ Praktik kesembuhan ilahi sering didasarkan kepada cerita-cerita injil yang menunjukan kuasa Yesus menyembuhkan orang-orang sakit bahkan membangkitkan orang mati. Di tangan gerakan ini, praktik kesembuhan ilahi dilakukan dengan keyakinan bahwa Allah berkenan menyembuhkan umatNya yang sakit, terkhusus bagi mereka yang mengalami kebuntuan dengan prosedur medis. Oleh karena itu, banyak orang Kristen yang berpartisipasi dengan 'iming-iming' kesembuhan, dan banyak diantara mereka yang mengharapkan kesembuhan itu merupakan para penyandang disabilitas.

Akan tetapi, praktik ini menyisakan kegelisahan besar bagi mereka yang tidak mengalami pemulihan karena akan dianggap sebagai orang yang kurang percaya dan berdosa. Sebaliknya, ada pandangan bahwa mereka harus benar-benar beriman agar dapat menerima kesembuhan dan kembali kepada kondisi hidup yang sehat dan normal. Bagi para penggiat praktik ini, manusia semestinya sempurna karena manusia adalah gambar Allah (Imago dei). Oleh karena itu, dalam praktik-praktik demikian, para penyandang disabilitas sering menjadi objek oleh orang-orang di sekelilingnya.

Sikap semacam ini tentu diakibatkan oleh pemahaman yang keliru terhadap persoalan disabilitas, sehingga membawa banyak umat Kristen kepada praktikpraktik yang seringkali tidak realistis bahkan dapat berujung kepada sikap-sikap diskriminatif terhadap para penyandang disabilitas. Pemahaman yang demikian terus menerus diwariskan melalui perangkat yang digunakan untuk menginternalisasikan nilai-nilai agama seperti musik atau yang dalam agama Kristen disebut musik gereja. Nilai-nilai yang merangsang kepedulian kepada sesama manusia kurang mendapat tempat dalam musik gereja, lain halnya dengan tema tentang kemahakuasaan Tuhan dan penyembahan yang selalu menjadi nilai utama dalam nyanyian-nyanyian gereja.

Berbeda dengan kekeliruan yang sering terjadi dalam komunitas Kristen, budaya populer dan segala produknya justru menunjukkan keramahannya kepada para penyandang disabilitas, salah satunya adalah musik pop. Sebagai salah satu produk budaya populer, musik pop yang dalam dikotomi antara yang sakral dan 
profan, seringkali dianggap bertentangan dengan musik-musik gerejawi, justru mengisi kepedulian terhadap para penyandang disabilitas yang tidak diisi gereja. Salah satu diantara musik pop yang menunjukkan keramahan dan inklusifitas kepada para penyandang disabilitas adalah lagu Fly karya Avril Lavigne yang diciptakan khusus kepada para penyadang disabilitas yang akan berkompetisi dalam special olympic yang diadakan di London tahun 2015. Lavigne dalam karyanya ini sengaja menuliskan lirik yang menunjukkan keberpihakan kepada para penyandang disabilitas sembari mengajak pihak lain menyambut para penyandang disabilitas dengan keramahan. Oleh karena itu, penting untuk menginterpretasi secara teologis lagu Fly karya Avril Lavigne yang berusaha menginternalisasi nilai-nilai keberpihakan terhadap isu disabilitas. Tulisan ini diharapkan menjadi awal bagi komunitas-komunitas religious, seperti gereja, khususnya di Indonesia untuk dapat belajar dari produk budaya populer.

\section{DISABILITAS DAN SIKAP GEREJA DI INDONESIA}

Sebelum menganalisis lebih jauh produk budaya populer yang berpihak kepada para penyandang disabilitas, seperti lagu Fly, penting sekali untuk melihat terlebih dulu gambaran singkat tentang pemahaman dan sikap gereja-gereja di Indonesia terhadap disabilitas dan para penyandangnya. Gambaran yang dimaksudkan adalah pandangan umum yang juga digunakan gereja bahwa disabilitas dipahami hanya sebatas kondisi-kondisi fisik yang tidak biasa. Sementara itu, memahami disabilitas memiliki kerumitannya tersendiri. Hal ini dikarenakan terdapat beberapa model yang berusaha untuk mendefinisikan secara tepat disabilitas, yaitu model moral, model sosial dan model medis. ${ }^{2}$

Model moral adalah model yang memberikan perhatian pada bagaimana disabilitas ditafsirkan sebagai baik atau buruk. Hal ini berhubungan dengan bobot moral seseorang yang menyandang disabilitas. Singkatnya, disabilitas dipahami sebagai akibat dari tindakan tidak bermoral dari orang dengan disabilitas atau keluarganya. Selain itu, dalam model ini juga para teolog sering mengaitkan disabilitas dengan nilai moral atau dosa dalam teks kitab suci seperti dalam Imamat 21: 16-24 yang melarang orang cacat untuk mendekati altar atau dengan kisah-kisah pelayanan Yesus yang menampilkan hubungan iman dan kesetiaan dengan penyembuhan. 
Sementara itu, model sosial melihat bahwa disabilitas merupakan sekelompok minoritas yang sering mengalami prasangka, pembatasan, diskriminasi dalam pekerjaan, dan banyak aspek hidup lainnya. Model ini tidak hanya meletakkan disabilitas dalam tataran fisik, tetapi juga dalam tataran asumsi dan sikap masyarakat terhadap mereka. Masyarakat membentuk struktur dan persepsi tertentu sehingga munculah klasifikasi cacat dan tidak cacat. Dengan demikian, masyarakat dapat dilihat sebagai faktor utama dalam mematikan potensi para penyandang disabilitas. ${ }^{3}$ Selain itu, dalam model ini juga istilah Abelism sering digunakan. Abelism adalah suatu istilah yang menandai setiap sterotipe yang menjadi hambatan dan kendala bagi para penyandang disabilitas sebagai sikap yang lumrah, bahkan dipandang sebagai sesuatu yang normal dan semestinya terjadi.

Model berikutnya ialah model medis. Model ini melihat tubuh ibarat sebuah mesin yang bekerja pada tingkat yang lebih tinggi atau lebih rendah, dimana disabilitas adalah kinerja tubuh yang rendah itu. Penekanannya pun berbeda dengan dua model sebelumnya, dimana disabilitas lebih diidentifikasi sebatas anatomi tubuh individual. Preferensi model ini adalah melihat disabilitas bisa kembali normal dengan cara dimodifikasi, ditutupi dan diperbaiki, agar orang yang cacat dapat dinormalkan kembali. Dalam model medis ini, para pengkotbah atau penginjil dari kalangan gerakan Pentakostal dan neo-Pentakostal, berperan sebagai healers, baik sebagai individu ataupun tim. Sementara praktik penyembuhan dapat dilakukan secara massal maupun privat. Menurut Rijnardus A. van Kooij, model ini paling sering diterapkan dalam konteks Indonesia. ${ }^{4}$

Dalam memetakan pemahaman dan respons gereja, ketiga model di atas mungkin sekali terlihat saling berkait kelindan dan membentuk sebuah cara pandang dalam memahami disabilitas. Namun demikian, Isabella Sinulingga dalam pengamatannya menemukan bahwa baik gereja maupun sekolah-sekolah teologi di Indonesia lebih cenderung memakai model medis ketika melihat keberadaan para penyandang disabilitas. Sedangkan model sosial atau model moral belum diperbincangkan secara mendalam. ${ }^{5}$

Penekanan model medis terhadap upaya menormalkan penyandang disabilitas, pada sisi lain, adalah sebuah tantangan. Tanpa disadari, konsekuensi dari normalisme tersebut adalah semakin seseorang memenuhi kebutuhan normalisme, 
semakin ia dipertimbangkan sebagai seorang manusia. Pada akhirnya, normalisme tersebut yang membuat para penyandang disabilitas menjadi objek pasif bahkan inferior dalam komunitasnya.

Pendapat Sinulingga ini tepat jika digunakan untuk melihat konteks bergereja di Indonesia saat ini, dimana para penyandang disabilitas seringkali disibukkan dengan praktik-praktik kesembuhan ilahi yang mendorong mereka untuk 'sembuh', yakni dapat melihat, berjalan, mendengar, sehat dan 'sempurna' seperti kebanyakan orang. Mayoritas warga gereja larut dalam kegemaran semacam ini sekalipun gerejanya (mainstream) secara institusi tidak mendukung bahkan menentangnya.

Sejatinya keinginan untuk "normal" ini tidak sepenuhnya keliru, sebab praktik penyembuhan pun merupakan bagian dari pelayanan Yesus dalam injil (Matius 4:23-25; 8:1-4; 9:1-8,927-31, Markus 1:40-45; 2: 1-12; 3:7-12, Lukas 5:12$16 ; 18: 35-43)$. Akan tetapi standar tentang sesuatu yang normal seperti ini pula yang mengakibatkan gereja bersifat eksklusif terhadap keberadaan para penyandang disabilitas. Gereja dapat menjadi tidak realistis melihat keberadaan para penyandang disabilitas, sehingga menuntut kesempurnaan dari mereka, ketimbang menyediakan ruang bagi mereka untuk menerima dan mengembangkan diri.

\section{MUSIK GEREJA MEWARISKAN PENYEMBAHAN ILAHI TANPA KEPEDULIAN SOSIAL}

Kesembuhan ilahi yang sering menempatkan para penyandang disabilitas sebagai objek, secara jelas merupakan potret gereja yang tidak peka dan realistis dalam memahami keberadaan para penyandang disabilitas. Sangat mungkin bahwa sikap ini diperoleh dari teologi-teologi gereja yang lebih mengarahkan perhatian kepada kehidupan yang akan datang, tentang surga, dan melupakan kenyataan hidup di dunia. Sebagai salah satu bentuk penyampaian nilai-nilai teologis, musik gerejawi pun mengidap masalah yang sama.

Gejala penekanan teologi yang futuristik ini dalam musik-musik gereja dikaji oleh Fiona Parascandalo. Menurutnya musik gereja merupakan media yang sangat efektif dalam mengkomunikasikan nilai dan norma agama kepada beragam pendengar. Tidak hanya itu, bahkan dalam konteks budaya populer saat ini, Christian Contemporary Music atau musik Kristen kontemporer, juga berguna untuk menjaga agar para pemuda Kristen tetap ambil bagian dalam komunitasnya. Dengan fungsi 
demikian, musik tidak hanya mentransfer nilai dan norma secara turun-temurun namun juga membatasi generasinya terhadap nilai dan norma non-Kristen. Musik Kristen kontemporer bahkan berusaha untuk mengontrol setiap individu sebagai bagian dari penerus nilai-nilai dan norma komunitasnya. ${ }^{6}$

Lebih jauh, Parascandalo melihat bahwa baik musik gereja tradisional dan musik kontemporer sama-sama memiliki tendensi kuat untuk berbicara tentang Tuhan, surga, maupun hukuman. Menurutnya, peran musik dalam ritual ialah sebagai pengingat bagi komunitasnya untuk kembali pada tradisi mereka. Dengan kata lain, ritual dimana musik sangat berperan sering digunakan untuk mempertahankan struktur anggota sebuah komunitas. Oleh karena itu, dalam upaya mempertahankan struktur dan otoritas komunitas kepada setiap individu, maka penting untuk menanamkan nilai serta norma yang mengikat. Perascandalo menggunakan teori Jeremy Bentham tentang Panopticon yang merupakan metafora tentang bagaimana kekuasaan ditegakkan ibarat "menara pengawas" dalam melihat kecenderungan yang ada dalam musik-musik gereja. Parascandalo menuturkannya sebagai berikut:

The panopticon, it is a metaphor for how the mechanisms of power are enforced At the centre of the panopticon is a watchtower where a prison guard observes all actions of the prisoners, who believe they are under constant surveillance because of the presence of the central tower. Yet the construction of the prison does not allow the prisoners to equally observe the actions within the tower The tower puts into action the disciplinary mechanisms of the normalizing gaze, initiating the subjectification process of those under its authority. ${ }^{7}$

Parascandalo melihat bahwa dalam kekristenan, menara pengawas itu diumpamakan dengan kehadiran Tuhan. Dalam gambaran beberapa teks kitab suci, kemahakuasaan Tuhan menghasilkan umat yang hidup di bawah pengawasan ilahi yang menjadikan mereka taat serta tunduk kepada otoritas Tuhan. Parascandalo menuturkannya lebih lanjut:

Within the Christian faith, God takes on the role of the guard in the watchtower. He established the norms which are to be followed within the faith and the punishments that are faced when the norms are not conformed to. God does not have to make his presence known; his power is that his authority is maintained by the internalization of his gaze. The Christian community is penetrated by the gaze and its disciplinary mechanisms. ${ }^{8}$ 
Musik gereja menurut Parascandalo baik tradisional maupun kontemporer mengambil peran sebagai pengingat akan pengawasan Tuhan yang konstan dalam hidup manusia. Hal ini terlihat dari banyaknya lagu dalam musik gereja yang tidak hanya berisi nilai sukacita dan kebahagiaan, namun juga tentang hukuman yang menanti bagi mereka yang memilih mengikuti norma yang lain. Para musisi gereja dalam hal ini telah menginternalisasi ajaran Kristen tertentu dan secara umum telah menginjili komunitas mereka sendiri.

Analisis Parascandalo dapat membantu untuk memahami kecenderungan musik gerejawi yang sejak dulu didominasi oleh tema-tema seperti Tuhan, surga, dan hukuman dalam gereja-gereja di Indonesia. Seperti yang terlihat dalam kidung jemaat yang lazim digunakan oleh gereja-gereja mainstream di Indonesia. Teologi dalam Kidung Jemaat sebagian besar menginternalisasikan teologi tentang kemahakuasaan Tuhan. Misalnya dalam bagian Kidung Jemaat dengan tema nyanyian "hidup beriman sehari-hari "(KJ No.35-471) dimana hampir semua lagunya berisi tentang kemahakuasaan dan otoritas Tuhan dalam hidup manusia. Hubungan dengan kehidupan sehari-sehari tetap dilihat dalam relasi manusia dengan Tuhannya.

Berbeda dengan tema lagu kebangsaan misalnya, hanya terdiri dari dua lagu saja yakni KJ No. 336 dan 337. Sama halnya dengan tema panen dan musim yang hanya terdiri dari tiga lagu yakni KJ No. 333-335. Dapat disimpulkan bahwa dalam nyanyian seperti Kidung Jemaat, lebih didominasi oleh teologi tentang kemahakuasaan Tuhan dan keimanan dalam dimensi futuristic, sedangkan isu-isu sosial tidak mendapat tempat dalam nyanyian-nyanyian jemaat.

Hal senada juga tampak dalam musik-musik Kristen kontemporer, aekalipun oleh para pendukung musik tradisional, musik Kristen kontemporer dikritik karena dianggap telah kehilangan rasa hormat yang pantas kepada Tuhan. Para pendukung musik kontemporer tetap merasa jika musik kontemporer lebih sesuai dengan norma dan budaya di sekitar mereka. Selain itu, musik kotemporer dianggap tidak sama dengan musik tradisional yang kaku dan formal. ${ }^{9}$ Akan tetapi, musik Kristen kontemporer seringkali hanya berfokus pada perubahan genre sedangkan nilai-nilai dalam musik tradisional masih dipertahankan. Tak heran jika tekanan akan keberimanan yang futuristik dalam nyanyian-nyanyian tradisional tidak benar-benar hilang dalam nyanyian kontemporer gereja. 
Sungguh disayangkan jika musik sebagai salah satu media yang efektif untuk menginternalisasikan ajaran-ajaran Kristen tidak menyentuh masalah yang sedang dihadapi umat seperti keberadaan penyandang disabilitas. Sementara musik gereja justru malah mempertahankan internalisasi nilai teologis yang hanya mengarah kepada relasi dengan Tuhan dan kehidupan yang akan datang. Tidak heran jika ketidakberpihakan gereja terhadap penyandang disabilitas terjadi terus menerus dikarenakan nilai-nilai teologis yang diwariskan dari generasi ke generasi, seperti dalam musik gereja, hanya yang berhubungan dengan surga, hukuman dan kehamakuasaan Tuhan semata.

\section{PRODUK BUDAYA POPULER DAN KEBERPIHAKAN KEPADA PENYANDANG DISABILITAS}

Respons gereja yang sedemikian lambannya terhadap keberadaan para penyandang disabilitas, telah membuat gereja jauh tertinggal jika dibandingkan dengan sikap inklusif yang ditunjukan oleh budaya populer dan produk-produk yang dihasilkannya. Gordon Lynch misalnya, melihat bahwa budaya populer yang kehadirannya ditandai sebagai lawan terhadap high culture, juga sebagai sebuah bentuk sosial dan resistensi kultural terhadap budaya dominan dan budaya massal. Menilik penyebarannya, Detweiler dan Taylor menilai bahwa budaya populer dalam segala bentuknya memerlukan pendengar massal yang tercipta melalui urbanisasi dan demokratisasi dalam kaitan dengan teknologi distribusi massal. ${ }^{10}$

Dari definisi dan karakteristik seperti ini maka produk-produk budaya populer seperti musik pop, film, televisi, selebriti, olahraga, dsb., diperkenalkan lewat media massa dan dikonsumsi secara luas tanpa batas, sehingga dapat disebut sebagai produk budaya populer. Produk budaya populer yang cukup menginklusi para penyandang disabilitas misalnya dapat dilihat dari keberadaan televisi, sekalipun secara etis sering menjadikan para penyandang disabilitas sebagai bahan humor. ${ }^{11}$ Namun demikian, stasiun televisi pada sisi lain terus berbenah dan menjadikan dirinya sebagai media yang ramah kepada para penyandang disabilitas. Talk show seperti Kick Andy misalnya, sering mewawancarai para penyandang disabilitas yang hidup mandiri dan melakukan aktivitas sehari-hari dengan cara yang berbeda. Dampak dari program televisi ini tidak hanya meningkatkan apresiasi dan 
kesadaran masyarakat akan hak-hak para penyandang disabilitas, ${ }^{12}$ tetapi juga menjadi gambaran adanya rasa haus akan perhatian, sentuhan bahkan pemulihan yang tidak disentuh oleh komunitas agama seperti gereja. ${ }^{13}$

Dalam penayangan program, stasiun televisi memperhitungkan keberadaan para penyandang disabilitas yang mengalami kekurangan pada pendengaran (tunarungu). Berbeda dari wajah stasiun televisi terdahulu yang hanya menampilkan berita secara visual maupun audio, stasiun televisi masa kini juga dilengkapi dengan running text dan bahasa isyarat dalam menampilkan berita. Tujuannya ialah agar dapat mengakomodir kebutuhan para penyandang disabilitas yang mengalami gangguan pendengaran.

Tak hanya televisi, produk budaya populer lain yang telah mengakar dalam kehidupan masyarakat, seperti smarthphone, turut menunjukan keberpihakannya kepada penyandang disabilitas. Lihat saja bagaimana Google melakukannya lewat fitur suara "Ok Google". Dengan fitur tersebut, setiap pengguna dapat melakukan penelusuran internet, mendapat penunjuk arah, hingga membuat pengingat. Belum lagi aplikasi Google Now, sebuah asisten pribadi cerdas yang dapat membantu setiap penggunanya mengakses smarthphone hanya dengan suara. Tentu semua kemudahan ini sangat membantu dan mengakomodir kebutuhan khusus para penyandang disabilitas yang mengalami keterbatasan penglihatan.

Selain televisi dan smarthphone, olahraga (sport) sebagai salah satu produk budaya populer, yang menurut Amos Yong, seringkali diibaratkan sebagai berhala karena dipandang sebagai sarang perjudian, mempertontonkan budaya kekerasan, kecurangan (kasus dopping para atlet), kompetisi yang menumbuhkan egoisme hingga lahan subur korupsi. Akan tetapi pada sisi lain Amos Yong melihat bahwa Paralympic dan Special olympic yang dikhususkan kepada para penyandang disabilitas sering membawa pesan yang mengkritik nilai-nilai dari olahraga kontemporer, dengan menawarkan motivasi untuk bertemu orang lain, membangun hubungan, mengadakan perjalanan bersama, bahkan berpusat dari kegembiraan melakukan aktivitas itu sendiri. ${ }^{14}$

Selain ketiga produk itu, musik barangkali adalah salah satu produk budaya populer yang sering menjadi media bagi para musisi menyatakan keberpihakannya terhadap isu sosial tertentu. Lihat saja bagaimana Lady Gaga lewat lagunya yang berjudul Born This Way, menampilkan dirinya sebagai aktivis yang membela hak- 
hak kaum disabilitas hingga LGBT. Gaga secara terang-terangan melakukan perlawanan dengan suara yang merdu tanpa memperdebatkan karya-karyanya. Hal ini ditegaskan oleh Mathieu Deflem yang melihat bahwa para penyanyi musik pop seperti Lady Gaga, berkontribusi terhadap isu-isu sosial lewat karya mereka tanpa harus menampilkannya dalam debat-debat publik. ${ }^{15}$

Kendati sering dipandang kurang serius untuk dibawa ke ranah akademis dan religius, serta dianggap hanya mengincar keuntungan sebagai komoditas ekonomi, banyak juga penyanyi musik pop yang menampilkan perjuangannya dalam membela hak-hak kaum yang terpinggirkan dalam masyarakat. Dalam isu disabilitas misalnya, muncul nama musisi seperti Avril Lavigne yang concern dalam membantu kehidupan para penyandang disabilitas yang berada di Amerika, Kanada dan beberapa wilayah lain.

Menurut berbagai informasi yang dapat diakses melalui internet, Avril Lavigne bernama lengkap Avril Ramona Lavigne, lahir di Belleville, Ontario, Kanada pada 27 september 1984. Ia berasal dari Kanada namun juga memiliki keturunan Perancis. Lavigne aktif bermusik sejak tahun 1999 dan telah merilis lima album dengan penjualan tertinggi mencapai 40 juta keping sehingga menjadikannya sebagai salah satu penyanyi dunia dengan penjualan album tertinggi sepanjang masa.

Mirip dengan Lady Gaga yang merupakan aktivis pembela hak-hak LGBT, Avril Lavigne sejak dulu memang terkenal dengan kepeduliannya kepada para penyandang disabilitas. Khusus pada 15 september 2010, Lavigne mendirikan sebuah yayasan sosial yang serius membantu anak-anak berkebutuhan khusus yang ia namakan The Avril Foundation. Pada channel Youtube-nya Lavigne gencar melakukan penjualan $t$-shirt dan berbagai konser amal, yang $100 \%$ keuntungannya diberikan kepada The Avril Foundation yang akan mengadakan berbagai kegiatan yang membantu anak-anak penyandang disabilitas di Amerika, Kanada, dll.

\section{LAGU FLY SEBAGAI WUJUD KEBERPIHAKAN BUDAYA POPULER TERHADAP DISABILITAS}

Dalam perjalanan karirnya, Avril Lavigne pernah menulis dan menyanyikan sebuah lagu berjudul Fly pada tahun 2015. Fly bukanlah lagu biasa, karena Lavigne 
menulis dan menyanyikannya sebagai dukungan terhadap Special Olympics World Games, olimpiade olahraga bagi penyandang disabilitas yang diselenggarakan pada tahun 2015 di Amerika. Dalam menulis lagu tersebut, Lavigne ditemani suaminya Chad Kroeger dan David Hodges. Inspirasi dari setiap lirik lagu ini didapat Lavigne dari anak-anak penyandang disabilitas yang ditemuinya di yayasan yang ia dirikan sendiri, dan juga dari para atlit disabilitas yang akan berlaga di Special Olympic. Bagi Lavigne, mereka adalah lagu itu sendiri. Lagu Fly sendiri terdiri dari lima bait, dua bait diantaranya merupakan reff dan ending dari lagu itu. Berikut ini adalah lirik dari lagu Fly karya Avril Lavigne:

(Bait 1)

There's a light inside all of us It's never hiding you just have to light it, It's the one thing that you got to trust It's like a diamond, you just have to find it

So if you ever feel like giving up.

Yeah, just remember that Reff:

We were all meant to fly. Spread your wings, across the universe. It's your time to, it's your time to shine

There's a light inside all of us.

Soon, you'll find that it's your time to fly.

Your time to fly

(Bait3)

A little help is all it ever takes. Somebody has to tell you that it's worth fighting.

A single step becomes a leap of faith.

That's when you realize you started flying.

So, don't you ever say you're giving up.

No, there's no looking back

(Bait4)

Just reach up, don't give up.

Until you touch the sky.

Just reach up, don't give up.

Until you've realized

Berdasarkan liriknya, sekilas lagu ini mirip dengan theme song pada event olahraga lainnya yang bertujuan untuk memotivasi para atlit atau peserta. Namun, dalam konteks yang ditujukan kepada para atlet yang merupakan penyandang disabilitas, lagu "Fly" tersebut tentu mengandung makna dan sentuhan yang berbeda dengan theme song kegiatan olahraga pada umumnya. 
Dari penafsiran terhadap narasi/lirik bait pertama, bait kedua dan bait keempat, tampak bahwa pesan dari lagu tersebut lebih diarahkan kepada para penyandang disabilitas untuk memotivasi, menumbuhkan kepercayaan diri dan menemukan potensi diri. Misalnya baris kedua dari bait pertama yang berbunyi, "It's never hiding you just have to light it." Penggalan lirik ini menunjukkan bahwa potensi itu seperti cahaya yang ada dalam diri setiap orang namun perlu dinyalakan. "It's like a diamond, you just have to find it", potensi dalam diri penyandang disabilitas diibaratkan seperti berlian yang hanya perlu ditemukan dan dipoles agar bernilai.

Semangat yang dinyatakan melalui lirik lagu Fly tidak sekadar diarahkan kepada usaha memenangkan sebuah pertandingan, namun lebih kepada menemukan potensi dan kepercayaan diri para penyandang disabilitas. Motivasi untuk menemukan potensi dalam diri para penyandang disabilitas berhubungan erat dengan abelism dalam bentuk streotipe buruk atau aturan-aturan yang mendiskriminasi. Akan tetapi dengan cara yang sesuai seperti Special Olympic potensi dari para penyandang disabilitas ini dapat bercahaya dan menjadi bernilai.

Selain lirik yang memotivasi, lirik lainnya yang berbunyi "There's a light inside all of us" dan "we were all meant to fly", menunjukkan bahwa ada kesetaraan yang hendak dibangun oleh Avril Lavigne. Kata "us" tidak hanya terbatas kepada para penyandang disabilitas saja namun manusia secara umum. Entah kebetulan atau tidak, sebelum menulis lagu ini Lavigne telah vakum dari dunia musik selama dua tahun akibat penyakit Lyme Disease yang dideritannya. Setelah menjalani perawatan khusus dan istirahat total, Lavigne dapat pulih dari penyakitnya dan menulis lagu Fly sebagai karya pertama pasca-kesembuhannya.

Dari pengalamannya bangkit dari sakit yang ia alami, Lavigne ingin mengirimkan pesan yang memotivasi setiap orang untuk dapat mengatasi tantangan sesulit apapun. Khususnya bagi para penyandang disabilitas, Lavigne membangun sebuah gambaran manusia yang sejati, yaitu manusia yang memiliki kekurangan dan potensi dalam dirinya. Akan tetapi, para penyandang disabilitas memiliki masalah krisis kepercayaan diri, dan terkungkung pada keterbatasan yang malah memadamkan potensi dalam diri mereka. 
Berbeda dari bait-bait sebelumnya, lirik dari bait ketiga dikhususkan kepada pihak lain dalam lingkungan sosial para penyandang disabilitas agar dapat memahami, memotivasi dan memberi dukungan kepada mereka. Makna ini jelas tersirat dalam lirik yang berbunyi "A little help is all it ever takes" dan "somebody has to tell you that it's worth fighting" pada baris satu dan dua pada bait ketiga. Dari pengalamannya yang concern membantu para penyandang disabilitas lewat yayasan The Avril Lavigne Foundation, Lavigne sadar bahwa peran lingkungan sosial sangatlah krusial bagi para penyandang disabilitas menemukan potensi dan menumbuhkan kepercayaan dalam diri mereka. Sebab sebuah komunitas yang tidak menerima dan menerapkan abelsm, justru mematikan kepercayaan diri dan potensi dalam diri para penyandang disabilitas. Oleh sebab itu, bantuan ini sangat dibutuhkan bagi setiap penyandang disabilitas.

Tidak hanya menyuarakan motivasi dan gambaran manusia yang sejati, lagu Fly karya Avril Lavigne juga sarat dengan makna-makna teologis. Sekalipun dikarang dan dinyanyikan kepada para penyandang disabilitas dalam konteks sebuah turnamen olahraga, namun kita tetap bisa membangun refleksi teologis dar lagu tersebut. Dari analisis naratif terhadap lirik lagu ini, jelas bahwa terkandung makna yang dapat direfleksikan secara teologis. Setidaknya ada dua refleksi teologis yang dapat mencirikan keberpihakan kepada para penyandang disabilitas dari lagu ini, dijelaskan sebagai berikut.

\section{- Gambar Allah yang indah}

Seperti yang dipaparkan pada bagian awal bahwa model medis masih cukup dominan dalam pemahaman gereja tentang disabilitas, maka normalisme yang menjadi bingkai dari model medis dalam mendefenisikan disabilitas pun harus dicermati. Menurut Sinulingga, dalam studi disabilitas, normalisme telah dipahami sebagai bingkai mengada yang sah di dunia dan menjadi satu-satunya ukuran hidup yang baik. Konsekuensi dari normalisme adalah menjadikan pribadi dengan disabilitas hanya dianggap sebagai objek yang pasif. ${ }^{16}$ Melalu lagu Fly, normalisme ini juga berusaha dilawan oleh Lavigne dengan menegaskan bahwa setiap manusia memiliki potensi, seumpama cahaya dan berlian. Lavine menolak generalisasi dan menekankan keunikan setiap manusia dalam lagunya.

Akan tetapi berbeda dengan Lavigne, 'penyakit' normalisme dalam melihat para penyandang disabilitas pun terjadi di banyak gereja. Ajaran tentang manusia 
sebagai gambar Allah (Image of God) tidak diletakan pada posisi teologis yang semestinya namun diletakan dalam kerangka normalisme manusia. Sehingga para penyandang disabilitas, kaum homoseksual, transgender atau kelompok yang jauh dari kacamata normalisme diistilahkan sebagai gambar Allah yang rusak.

Padahal, gambar Allah dalam konsep kekristenan sejatinya dapat mendorong gereja untuk memahami keberadaan para penyandang disabilitas. Sebab jika dilihat lebih jauh dalam kitab Kejadian, semua manusia pada dasarnya sudah memiliki keindahan sejak diciptakan (Kejadian 1:26-27;31). John Novane, sebagaimana yang dikutip Sinulingga, melihat manusia sebagai gambar Allah yang semestinya dilekatkan dengan Sang Pencipta itu sendiri. Novane melihat bahwa semua yang diciptakan berasal dari Allah sebagai hakikat keindahan. Hal itu bukan hasil manusia melainkan pemberian Allah secara cuma-cuma. Sayangnya, keindahan sering dipahami dengan sangat terbatas. Keindahan dipandang hanya sebatas sesuatu yang menggiurkan saja. ${ }^{17}$ Tak heran jika para penyandang disabilitas dipaksa untuk menjadi 'normal' seperti kebanyakan orang.

Bergerak dari keindahan yang semu dan menggiurkan kepada Allah sebagai sumber dari keindahan itu, maka para penyandang disabilitas pun dapat dipandang dari sudut yang lebih baik. Para penyandang memiliki keindahannya sendiri sebagai pemberian Tuhan yang mestinya dipahami oleh setiap orang. Keindahan, yang oleh Avril Lavigne dibahasakan sebagai cahaya dan berlian yang ada dalam diri para penyandang disabilitas, hanya perlu ditemukan dan dinyalakan. Akan tetapi, gerejagereja agaknya lebih senang dengan normalisme yang justru menenggelamkan kemilau cahaya dan berlian itu.

\section{- Menjadi gereja yang hospitable}

Lavigne mendorong masyarakat agar menjadi peduli dengan diskriminasi yang kerap kali dialami oleh para penyandang disabilitas. Melalui lagu Fly ataupun The Avril Lavigne Foundation, Lavigne berupaya untuk memberi bantuan dan motivasi kepada para penyandang disabilitas. Bukankah dalam posisi ini gereja telah sedemkian jauh tertinggal? Alih-alih memberi ruang bagi para penyandang disabilitas, gereja justru menutup pintunya rapat-rapat dan menjadi nyaman dengan abelism. 
Bergerak dari eksklusifitas ini, semestinya gereja dapat belajar dari produkproduk budaya populer agar dapat mengubah citra yang lekat dengan diskriminasi kepada para penyandang disabilitas itu. Citra itu dapat ditelaah dari gagasan John Swinton dalam tulisannya "From Inclusion to Belonging" tentang menjadi komunitas iman yang mempraktikan keramahtamahan (hospitality) kepada para penyandang disabilitas. Swinton melihat pelayanan Yesus dalam injil sejatinya menampilkan irama (rhytm) hospitalitas itu. Swinton menyatakan, "One of the things that we sometimes miss within Jesus' ministry is the odd shape of his hospitality. Sometimes he was a guest in people's houses, and sometimes he was a host. This constant movement from guest to host is a primary mark of the incarnation."18

Irama hospitalitas itu terwujud dari peran Yesus yang terkadang menjadi seorang tamu namun juga dapat menjadi tuan rumah bagi orang-orang yang termarginalkan, seperti penyandang disabilitas. Ketika Yesus duduk dan makan bersama pemungut cukai dan orang-orang berdosa (Matius 11:19), Yesus tidak bermaksud mengubah mereka. Oleh sebab itu, Dia dituduh sama seperti mereka. Meski demikian, Yesus tetap duduk bersama dengan mereka, menawarkan persahabatan, menunggu untuk belajar bersama mereka. Lebih dari itu, dalam keramahtamahan-Nya, Yesus pun bertanya apa yang mereka inginkan terlebih dahulu (Markus 10:21).

Dari gagasannya ini Swinton menunjukan bahwa sikap gereja yang menginklusi para penyandang disabilitas dalam komunitas saja tidaklah cukup. Pasalnya, menginklusi tidak menjadikan para penyandang disabilitas sebagai bagian integral dari komunitasnya. Gerakan menginklusi hanya akan membuat gereja terus menjadi tuan rumah yang melakukan sesuatu bagi para penyandang disabilitas. Bergerak lebih jauh dari itu, gereja menurut Swinton semestinya dapat menjadi komunitas yang lebih melakukan hospitalitas (hospitality) kepada para penyandang disabilitas. Gereja tidak sekadar merangkul para penyandang disabilitas ke dalam komunitas, namun juga menempatkan mereka sebagai bagian yang integral dari komunitas. Tidak sekedar menyambut para penyandang disabilitas namun dapat belajar juga dari pengalaman-pengalaman mereka. ${ }^{19}$

Jika produk-produk budaya populer seperti lagu Fly, The Avril Lavigne Foundation atau Special Olympic menyediakan ruang khusus bagi penyandang 
disabilitas, maka gereja sebagai komunitas yang hospitable dapat menyediakan ruang bagi mereka untuk bersama dengan yang lain. Di satu sisi, ini perlu untuk memberikan kesempatan khusus bagi penyandang disabilitas agar mereka dapat mengenali diri mereka sendiri. Di sisi lain, menyediakan ruang bagi mereka bersama yang lain agar para penyandang disabilitas dapat menjadi subjek bagi dirinya sendiri.

\section{BELAJAR DARI LAGU FLY YANG RAMAH TERHADAP DISABILITAS}

Dengan makna teologis dari lagu Fly yang sangat berpihak kepada para penyadang disabilitas, maka relasi antara teologi Kristen dan budaya populer bukannya saling mengeliminasi dan meniadakan. Sebaliknya, seperti gagasan Gordon Lynch dalam model pendekatan revised correlational, menegaskan bahwa kebenaran bukan hanya milik tradisi religius saja. Komunitas religius apapun dapat merangkai relasi dialektis yang membuat baik budaya populer maupun tradisi religius dimampukan untuk saling belajar. ${ }^{20}$

Gereja yang belajar dari produk-produk budaya populer bukanlah sebuah kemustahilan. Sinyalemen ke arah itu telah diperlihatkan April Vega dalam artikel yang berjudul "Music Sacred and Profane: Exploring the Use of Popular Music in Evangelical Worship Services." Dalam penelitiannya, Vega menemukan beberapa gereja evangelis di Amerika Serikat yang menggunakan musik populer dalam ritual ibadah mereka. Ada dua alasan yang mendasari penggunaan lagu populer tersebut. Pertama, beberapa jenis musik populer dinilai cukup membantu menyampaikan isi khotbah dan membangkitkan respon emosional pendengar. Kedua, penggunaan musik populer juga bertujuan untuk memperlihatkan bahwa pesan-pesan Kristen tidak hanya dibawa oleh gereja. Penggunaan musik populer secara teologis menunjukan bahwa pesan dari Tuhan dapat dibawa oleh siapapun dan dalam keadaan apapun. $^{21}$

Pesan dari Tuhan itu misalnya tampak dalam lagu Fly, yang secara teologis memiliki ajakan untuk memandang para penyandang disabilitas sebagai gambar Allah yang memiliki keindahan yang berbeda. Selain itu, juga membentuk sebuah komunitas yang menjadikan para penyandang disabilitas sebagai bagian integral dari sebuah komunitas seperti special olympic. Hal ini dapat menjadi kritik bagi gerejagereja di Indonesia terutama media yang digunakan untuk mewariskan nilai seperti 
musik, bahwa produk budaya populer seperti musik pop begitu peka terhadap ketidakberpihakan terhadap para penyandang disabilitas. Berbeda dengan musik gerejawi, musik pop justru mewariskan nilai-nilai keberpihakan kepada para pendayang disabilitas yang tidak sempat disentuh gereja.

\section{KESIMPULAN}

Berdasarkan uraian dalam makalah ini, intepretasi teologis menunjukan bahwa musik populer seperti Fly karya Avril Lavigne dapat membuat komunitas religius seperti Gereja belajar untuk menanggapi keberadaan para penyandang disabilitas secara lebih realitis. Gereja-gereja mestinya membuat perubahan pandangan yang menitikberatkan pada praktik-praktik penyembuhan ilahi kepada upaya menciptakan komunitas yang tidak hanya inklusif namun juga melakukan hospitalitas kepada para penyandang disabilitas. Lebih daripada itu, nilai-nilai untuk menciptakan komunitas yang ramah itu perlu diinternalisasikan bahkan diwariskan dalam perangkat-perangkat yang sering digunakan oleh gereja, seperti musik gereja. Dengan demikian, diharapkan agar nilai-nilai yang diwariskan gereja kepada umatnya tidak hanya berkutat pada penyembahan kepada Tuhan saja, namun juga merangsang umat untuk peka dengan keadaan sosial di sekitar mereka seperti keberadaan para penyadang disabilitas.

\section{Endnotes :}

\footnotetext{
${ }^{1} \mathrm{R}$ van Kooij and Y. Tsalatsa, Bermain Dengan Api (Jakarta: BPK Gunung Mulia, 2007), 19-20.

${ }^{2}$ Deborah Beth Creamer, "Disability Theology," Religion Compass 6, no. 7 (2012): 340-41.

${ }^{3}$ Creamer, 341.

${ }^{4}$ Kooij and Tsalatsa, Bermain Dengan Api, 19-20.

${ }^{5}$ Isabella Novsima Sinulingga, "Keindahan Dalam Disabilitas: Sebuah Konstruksi Teologi Disabilitas Intelektual," Indonesian Journal of Theology 3, no. 1 (2015): 37.

${ }^{6}$ Fiona Perascaldo, "Thou Shalt Get Thy Praise On!: Analysis on the Conversion and Community Maintenance Powers of Contemporary Christian Music," The Journal of Religion and Popular Culture 25, no. 2 (2013): 205-16.

${ }^{7}$ Perascaldo, 209.

${ }^{8}$ Perascaldo, 210.

${ }^{9}$ Mark Evans, Open up the Doors Music in the Modern Church (London: Equinox Publishing, 2006), $1-2$.

${ }^{10}$ Craig Detweiler and Barry Taylor, A Matrix of Meaning Finding God in Pop Culture (Michigan: Baker Academic, 2003), 18.

${ }^{11}$ Dicky Sofijan, Religion and Television in Indonesia: Ethics Surrounding Dakwahteiment (Geneva: Globethics.net, 2013), 74.
} 
12 Tabita Kartika Christiani, "Problems and Challenges of Persons with Disabilities in Indonesia Society from Christian Perspective," in Proceeding of the Workshop on Disability Discourse for Theological Institution in Indonesia, (Yogyakarta: Duta Wacana Christian University, 2011), 38.

${ }^{13}$ Detweiler and Taylor, A Matrix of Meaning Finding God in Pop Culture, 155.

${ }^{14}$ Amos Yong, "Running the (Special) Race: New (Pauline) Perspective on Disability and Theology of Sport," Journal of Disability \& Religion 18 (2014): 212-13.

${ }^{15}$ Mathieu Deflem, Lady Gaga and the Sociology of Fame (New York: Palgrave Macmillan, 2016), 8-9.

${ }^{16}$ Sinulingga, "Keindahan Dalam Disabilitas: Sebuah Konstruksi Teologi Disabilitas Intelektual,” 38.

${ }^{17}$ Sinulingga, 40-41.

18 John Swinton, "From Inclusion to Belonging: Why 'Disabled' Bodies Are Necessary for the Faithfulness of the Church," in Theology and the Experience of Disability: Interdisciplinary Perspectives from Voices Down Under, ed. Andrew Picard and Myk Habets (London: Routledge, 2016), 180.

${ }^{19}$ Swinton, 180-81.

${ }^{20}$ Gordon Lynch, Understanding Theology and Populer Culture (Malden: Blackwell Publishing, 2005), 99-101.

21 April Vega, "Music Sacred and Profane: Exploring the Use of Popular Music in Evangelical Worship Services," Journal of Religion and Populer Culture 24, no. 3 (2012): 23.

\section{DAFTAR PUSTAKA}

Christiani, Tabita Kartika. "Problems and Challenges of Persons with Disabilities in Indonesia Society from Christian Perspective." In Proceeding of the Workshop on Disability Discourse for Theological Institution in Indonesia,. Yogyakarta: Duta Wacana Christian University, 2011.

Creamer, Deborah Beth. "Disability Theology." Religion Compass 6, no. 7 (2012).

Deflem, Mathieu. Lady Gaga and the Sociology of Fame. New York: Palgrave Macmillan, 2016.

Detweiler, Craig, and Barry Taylor. A Matrix of Meaning Finding God in Pop Culture. Michigan: Baker Academic, 2003.

Evans, Mark. Open up the Doors Music in the Modern Church. London: Equinox Publishing, 2006.

Kooij, R van, and Y. Tsalatsa. Bermain Dengan Api. Jakarta: BPK Gunung Mulia, 2007.

Lynch, Gordon. Understanding Theology and Populer Culture. Malden: Blackwell Publishing, 2005.

Perascaldo, Fiona. "Thou Shalt Get Thy Praise On!: Analysis on the Conversion and 
Community Maintenance Powers of Contemporary Christian Music." The Journal of Religion and Popular Culture 25, no. 2 (2013).

Sinulingga, Isabella Novsima. "Keindahan Dalam Disabilitas: Sebuah Konstruksi Teologi Disabilitas Intelektual.” Indonesian Journal of Theology 3, no. 1 (2015).

Sofijan, Dicky. Religion and Television in Indonesia: Ethics Surrounding Dakwahteiment. Geneva: Globethics.net, 2013.

Swinton, John. "From Inclusion to Belonging: Why 'Disabled' Bodies Are Necessary for the Faithfulness of the Church." In Theology and the Experience of Disability: Interdisciplinary Perspectives from Voices Down Under, edited by Andrew Picard and Myk Habets. London: Routledge, 2016.

Vega, April. "Music Sacred and Profane: Exploring the Use of Popular Music in Evangelical Worship Services." Journal of Religion and Populer Culture 24, no. 3 (2012).

Yong, Amos. "Running the (Special) Race: New (Pauline) Perspective on Disability and Theology of Sport.” Journal of Disability \& Religion 18 (2014): 209-225. 